\title{
The Tectorial Membrane: Mechanical Properties and Functions
}

\author{
Jonathan B. Sellon, ${ }^{1}$ Roozbeh Ghaffari, ${ }^{1}$ and Dennis M. Freeman ${ }^{1,2}$ \\ ${ }^{1}$ Research Laboratory of Electronics, MIT, Cambridge, Massachusetts 02139 \\ ${ }^{2}$ Department of Electrical Engineering and Computer Science, MIT, Cambridge, Massachusetts 02139 \\ Correspondence: freeman@mit.edu; sellon@mit.edu; rooz@mit.edu
}

The tectorial membrane (TM) is widely believed to play a critical role in determining the remarkable sensitivity and frequency selectivity that are hallmarks of mammalian hearing. Recently developed mouse models of human hearing disorders have provided new insights into the molecular, nanomechanical mechanisms that underlie resonance and traveling wave properties of the TM. Herein we review recent experimental and theoretical results detailing TM morphology, local poroelastic and electromechanical interactions, and global spread of excitation via TM traveling waves, with direct implications for cochlear mechanisms.

\section{TECTORIAL MEMBRANE MORPHOLOGY AND COMPOSITION}

$T_{d}^{\text {he }}$ he tectorial membrane (TM) is a highly hydrated extracellular matrix that resides above the hair bundles of mechanosensory hair cells in the cochlea. Because of its strategic position above the bundles, the TM is believed to play a critical role in the stimulation of hair cells. Recently, genetic studies have confirmed the importance of the TM in hearing, whereby manipulations of genes targeting TM proteins have resulted in significant hearing deficits. These mutations cause severe hearing deficits, even when the TM is nearly unchanged in its physical orientation and structural attachments to the sensory receptors.

The TM's three main constituents are water (97\%), glycosaminoglycans ([GAGs], e.g., uronic acid and keratan sulfate), and collagenous (collagen II, IX, and XI), and noncollagenous proteins ( $\alpha$-tectorin, $\beta$-tectorin, CEACAM16, otogelin, and otogelin-like). Many of the TM's structural constituents are commonly found in connective tissues (Freeman et al. 2003) with the exception of the glycoproteins. The TMs $\alpha$ - and $\beta$-tectorin glycoproteins make up a large fraction of the TM's dry weight, and are constituents of the TM's striated sheet matrix (Killick et al. 1995; Legan et al. 2000), within which collagen fibrils are embedded and oriented in the radial direction perpendicular to the cochlear spiral (Fig. 1A).

Recent results reported by Andrade et al. (2016) provide high-resolution images of the TM's ultrastructure using immunogold labeling and high-resolution freeze-fracture replicas used to investigate the fine molecular makeup of TM molecules. Figure 1B shows parallel-oriented collagen bundles in the upper surface of the TM, extending from the spiral limbus toward the TM marginal band. The most superficial

Editors: Guy P. Richardson and Christine Petit

Additional Perspectives on Function and Dysfunction of the Cochlea available at www.perspectivesinmedicine.org

Copyright (C) 2019 Cold Spring Harbor Laboratory Press; all rights reserved; doi: 10.1101/cshperspect.a033514

Cite this article as Cold Spring Harb Perspect Med 2019;9:a033514 
J.B. Sellon et al.
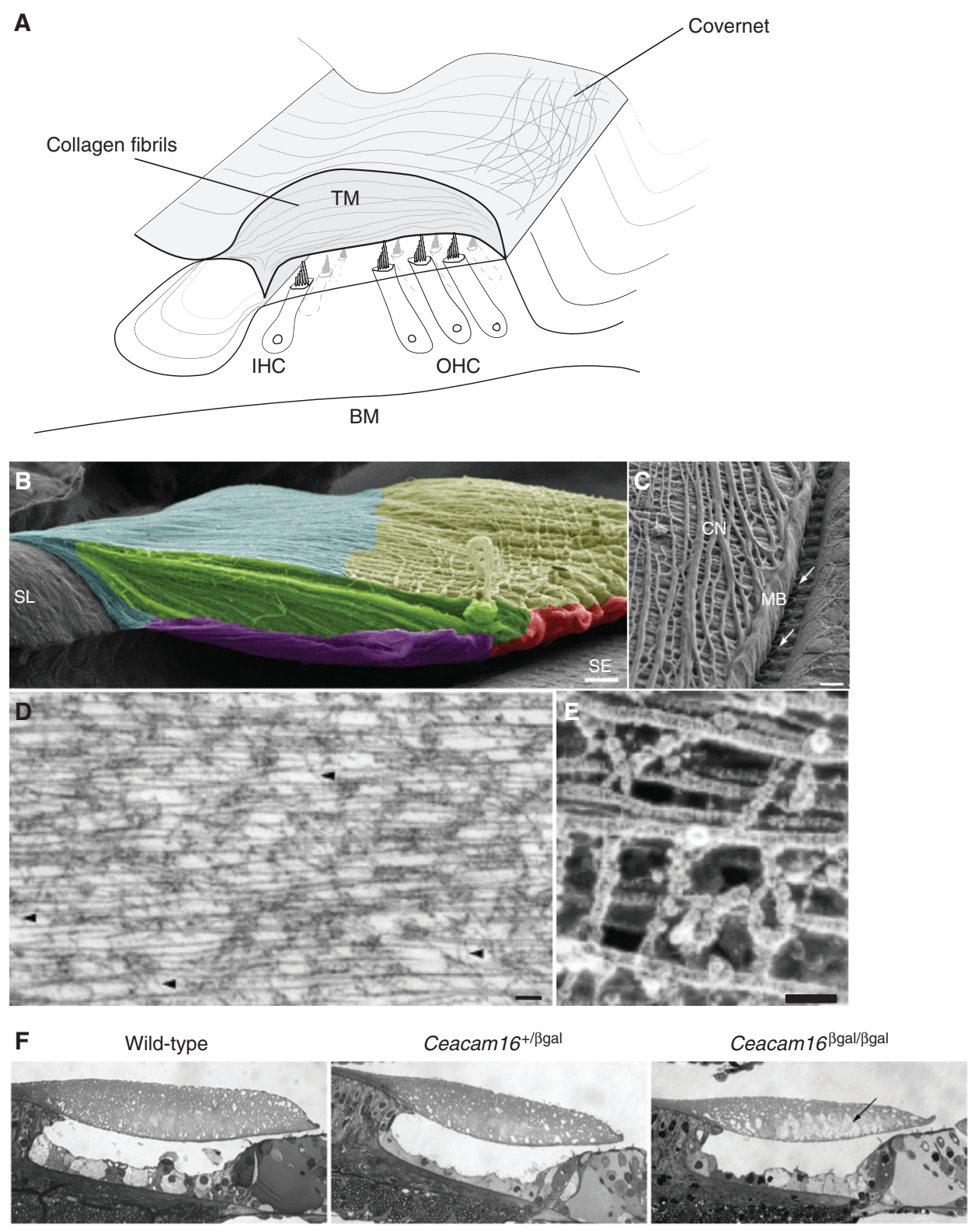

Figure 1. Tectorial membrane (TM) structure and morphology. (A) The TM is an extracellular matrix overlying cochlear hair bundles comprised of $97 \%$ water by weight, a collagen matrix, and an embedded striated sheet comprised of glycosaminoglycans and other noncollagenous proteins ( $\alpha$-, $\beta$-tectorin, and CEACAM16). (B) A scanning electron microscope (SEM) image of the TM attached to the spiral limbus (SL) and above the sensory epithelium $(\mathrm{SE})$ (blue = limbal region; yellow = covernet $[\mathrm{CN}]$; green $=$ striated sheet; red = marginal band $[\mathrm{MB}]$; purple $=$ Kimura's membrane). Scale bar, $15 \mu \mathrm{m}$. $(C)$ SEM image of the TM showing the top surface of the covernet region. Scale bar, $10 \mu \mathrm{m}$. (D) A transmission electron microscope (TEM) image of the TM. Arrowheads show the location of the type II collagen fibrils interwoven by thin filaments. Scale bar, $100 \mathrm{~nm}$. (E) Highresolution freeze-etching image of the TM formed by collagen fibrils cross-linked by filamentous materials. Scale bar, $50 \mathrm{~nm}$. (Panels $B-E$ from Andrade et al. 2016; reprinted, with permission, from Elsevier ( 2016 .) (F) SEM images of the TM within the cochlear partition in wild-type (left), Ceacam16 heterozygotes (middle), and Ceacam16 homozygotes (right). IHC, Inner hair cell; OHC, outer hair cell; BM, basilar membrane. (Panel $F$ from Cheatham et al. 2014; reprinted, with permission, from the Society for Neuroscience (c) 2014.) 
fibrillar bundles (covernet) obliquely cross the TM in the longitudinal direction (Fig. 1C). Collagen fibrils running through the TM are cross-linked (Fig. 1D) by thin filaments (Fig. $1 \mathrm{E})$. The nanopores in the TM are 10 s of nanometers in wild-type mice (Masaki et al. 2006; Sellon et al. 2014), and tend to vary across different mutant mouse models, as shown in recent studies detailing the Ceacam16 mutant mice (Fig. 1F) (Cheatham et al. 2014), which display spontaneous, stimulus-frequency, and transiently evoked otoacoustic emissions with markedly larger amplitudes. The striated sheet, nanopores, and embedded collagen fibrils create a highly inhomogeneous and anisotropic TM matrix that spans the entire length of the cochlea. This anisotropy gives rise to TM mechanical properties that vary in the longitudinal and radial directions (Abnet and Freeman 2000; Gu et al. 2005).

Mutant mouse models have revealed the structural importance of the tectorins as part of the striated matrix (Legan et al. 2005; Russell et al. 2007). Legan and colleagues (2014) examined three tectorin mutations, and found a number of morphological changes compared with wild types, such as reduced limbal zone, absence of striated-sheet matrix, disruption of collagen fibrils in the sulcal region, delamination of Kimura's membrane, detachment of Hensen's stripe, altered morphology of the covernet, and enlarged nanopores (Sellon et al. 2014). Furthermore, recent studies of the developing TM reveal the importance of the tectorins for establishing collagen fibril alignment within the tissue (Goodyear et al. 2017). These results highlight the importance of the tectorin proteins in controlling the nanoscale and macroscale structure of the TM.

\section{NANOSCALE STRUCTURE AND MATERIAL PROPERTIES}

Point-stiffness studies developed by von Békésy and Zwislocki were the first to explore the role of TM local mechanical properties (i.e., mass, stiffness) in stimulating the sensory hair bundles of hair cells (von Békésy 1960; Zwislocki 1980; Zwislocki and Cefaratti 1989). More recent mea- surements in mice and guinea pig preparations (Freeman et al. 2003; Shoelson et al. 2004; Gueta et al. 2006; Masaki et al. 2006; Richter et al. 2007) have shown that TM point stiffness varies from base to apex. However, there is considerable variability across the studies (by as much as a 100 -fold), in part because the TM is anisotropic, and also because the static and dynamic methods are different. It is now clear that the mechanical and material properties of the TM are frequency dependent and consistent with viscoelastic theory at the bulk level (Abnet and Freeman 2000; Gu et al. 2008), but it remains unclear how the TM locally interacts with the hair bundles at audio frequencies (Ghaffari et al. 2007).

The dynamic material properties of the TM are determined not only by the matrix of macromolecules, but also by their interactions with interstitial fluid. Forces of fluid origin depend on both the viscosity of the fluid and the distance between macromolecules, which can be characterized by an effective pore size (Masaki et al. 2006; Sellon et al. 2014). Because the TM contains a fixed charge and $97 \%$ of its mass is water (Freeman et al. 2003), it is hardly surprising that electrostatic and viscous properties of the TM are important. But what is more surprising is that TM dynamic interactions at the size scale of the hair bundles may be determined by both electrokinetic and poroelastic local phenomena, as opposed to stiffness alone. Recent findings show that the shear viscosity of the TM depends on porosity (Masaki et al. 2006; Ghaffari et al. 2013; Sellon et al. 2014), which underlies key differences in the cochlear phenotypes of Tecta ${ }^{\mathrm{Y} 1870 \mathrm{C} /+}$ and $\mathrm{Tectb}^{-/-}$mutants (Fig. 2A,B) (Sellon et al. 2014), and thus represents a critical property of the TM.

The nanoscale porosity of TM in combination with shear storage modulus and shear viscosity could contribute to local stimulation of the hair bundles. Hair cells are sensitive to shear forces that displace hair bundles along their axis of symmetry. Based on its strategic position overlying the hair bundles, the TM has been widely believed to deliver shear forces that stimulate hair cells at audio frequencies, consistent with a second-order system. However, the presence of fluid and pores in the TM suggests that 
J.B. Sellon et al.
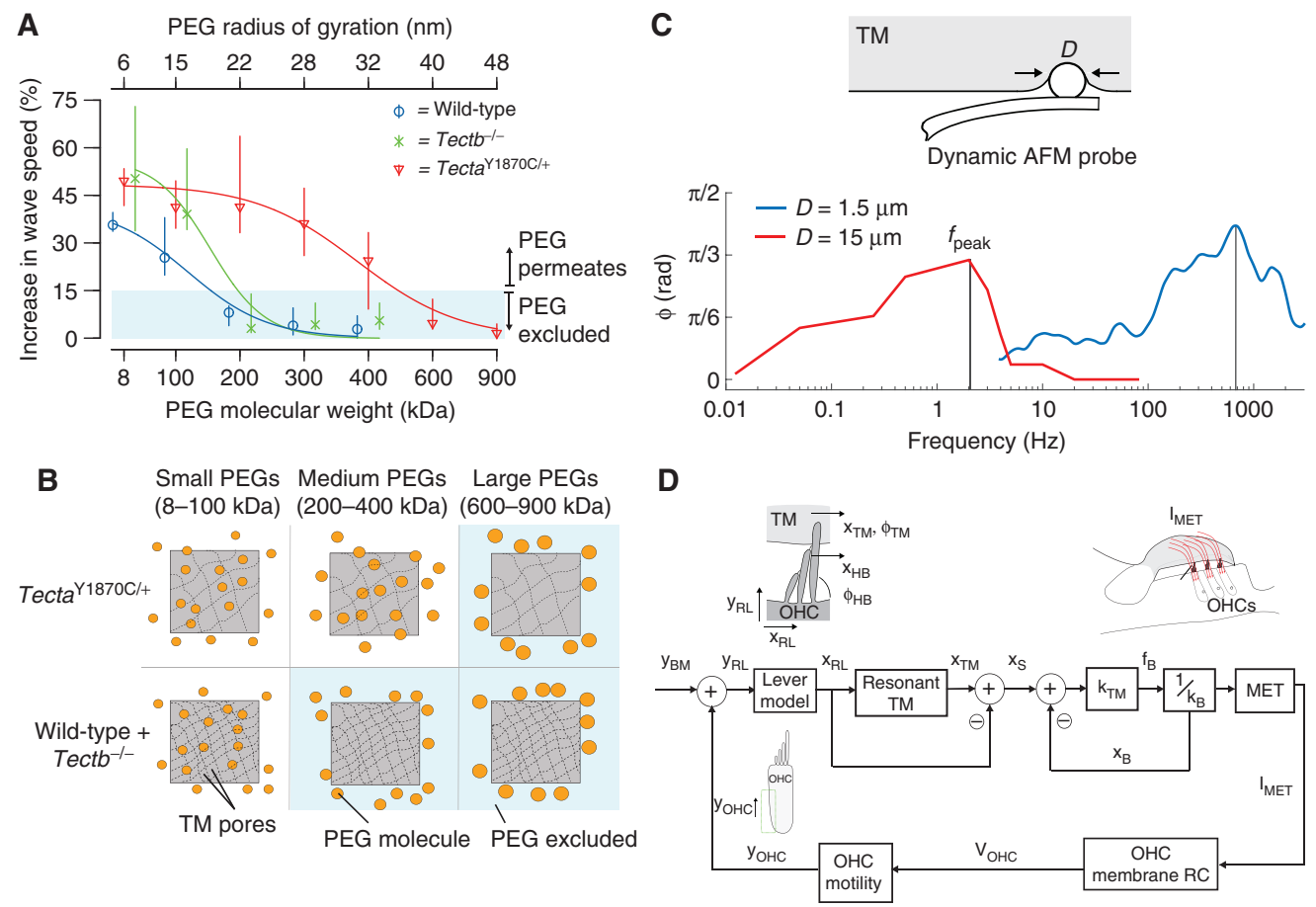

Figure 2. Role of tectorial membrane (TM) porosity in controlling local and global mechanical properties. (A) Polyethylene glycols (PEGs) with varying molecular masses ( $8 \mathrm{kDa}$ to $900 \mathrm{kDa})$ added to artificial endolymph surrounding Tecta ${ }^{\mathrm{Y} 1870 \mathrm{C} /+}, \mathrm{Tectb}^{-/-}$, and wild-type TMs cause changes in wave speed, implying differences in the nanoporous structure of these tissues. (B) Schematic illustration of the interaction between PEG molecules and the nanoporous structure of the TM. (Panels $A$ and $B$ reprinted, with permission, from Sellon et al. 2014.) (C) Schematic drawing and phase versus frequency response highlighting differences in phase of stimulation for hair bundle and stereocilia-sized probes. Poroelasticity theory predicts that the size of a probe (or hair bundle) in contact with a porous tissue would affect its phase of stimulation. (D) Depiction of how local mechanical properties of the TM can influence hair bundle mechanics and feedback loops in the cochlea. Displacement of the basilar membrane $\left([\mathrm{BM}] \mathrm{y}_{\mathrm{BM}}\right)$ displaces the reticular lamina $\left(\mathrm{x}_{\mathrm{RL}}\right)$, which then deflects outer hair cell $(\mathrm{OHC})$ hair bundles with a given TM displacement $\left(\mathrm{x}_{\mathrm{TM}}\right)$ and an angle $\phi$. This angle $\phi$ depends on the frequencydependent interactions of hair bundles with the poroelastic TM and the magnitude depends on the hair bundles stiffness $\mathrm{k}_{\mathrm{B}}$ and the TM stiffness $\mathrm{k}_{\mathrm{TM}}$. Deflection of hair bundles causes current to flow through mechanoelectrical transduction channels $\left(\mathrm{I}_{\mathrm{MET}}\right)$, charging $\mathrm{OHC}$ capacitance, which applies a voltage on the OHC membrane $\left(\mathrm{V}_{\mathrm{OHC}}\right)$ and ultimately triggers $\mathrm{OHC}$ motility with given displacement $\left(\mathrm{y}_{\mathrm{OHC}}\right)$. AFM, Atomic force microscope.

the phase angle and magnitude of TM-hair bundle displacements are frequency-dependent, leading to more complex frequency-dependent interactions than previously thought (Nia et al. 2011). Application of nanoindentations at audio frequencies causes a mechanical frequency response of the TM, which shows a prominent phase lead at middle frequencies (Fig. 2C). At low frequencies, the mechanical response approaches an asymptotic value corresponding to equilibrium elastic response. At higher frequencies, the modulus approaches another asymp- totic value and undergoes a change in phase that peaks and decreases with frequency. According to poroelastic theory, altering the size of the atomic force microscope (AFM) probe tip causes the characteristic length over which fluid flows to change, thereby altering the coupling and peak frequency of the phase angle (Nia et al. 2015). Thus, the TM's poroelastic response may be highly dependent on the size of the hair bundles. By altering the local phase of the hair bundles versus the displacement of the reticular lamina, the TM's poroelastic properties may also 
TM Mechanical Properties and Functions

alter timing and polarity of cochlear feedback paths (Fig. 2C), and this phase lead may help overcome the variety of phase lags that are present throughout the cochlea and thus contribute to the sensitivity of mammalian hearing.

\section{FIXED CHARGE AND ELECTROKINETICS}

In addition to glycoproteins and collagen, biochemical studies have long established that the
TM contains highly charged GAGs (Steel 1983; Ghaffari et al. 2013). These fixed charge groups are fully ionized at physiological $\mathrm{pH}$ and neutralized at acidic pHs. Quantifying the density of fixed charge $\left(c_{f}\right)$ in the TM is important for understanding the mechanical properties of the TM (Fig. 3A). Traditional electrical recording techniques that require micropipettes have been largely unsuccessful in measuring $\mathrm{TM} c_{f}$ because producing stable voltages across the

A

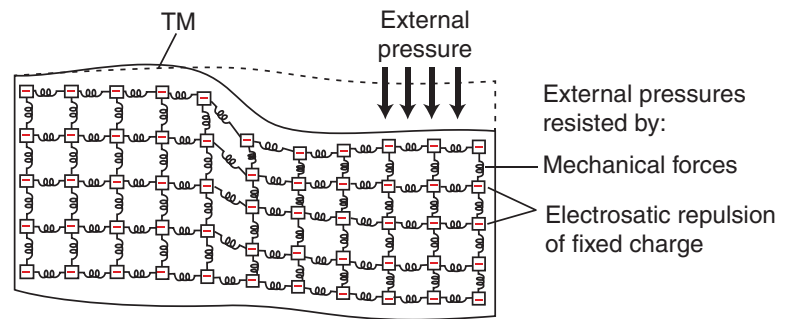

B

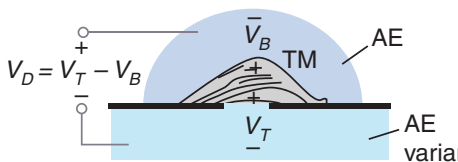

C
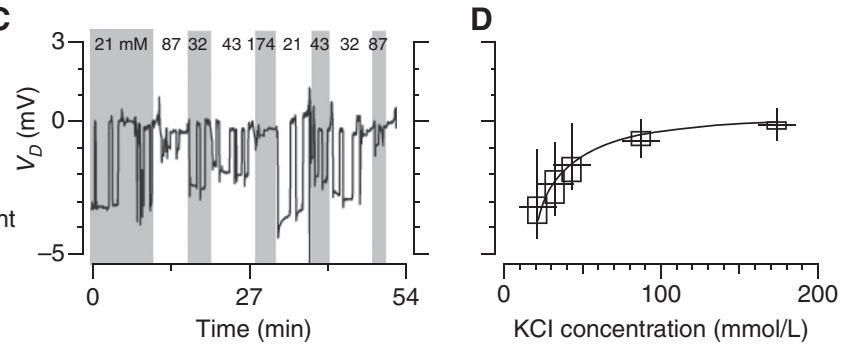

$\mathbf{E}$

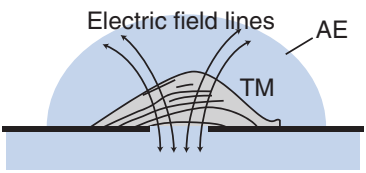

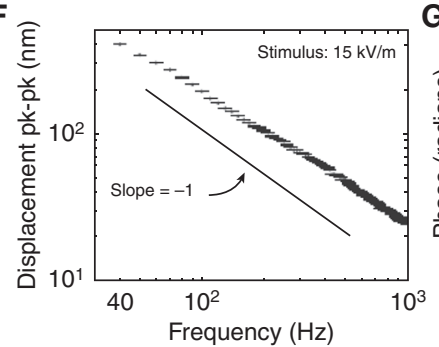

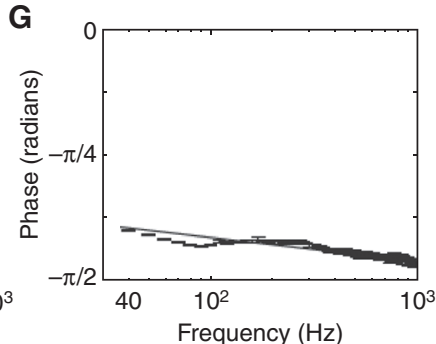

Figure 3. Localized electrokinetic properties of the tectorial membrane (TM). (A) Schematic drawing of the TM showing negative fixed charge groups attached to a network of collagen fibers (represented by mechanical springs). (B) Schematic drawing of the microaperture chamber showing isolated TM segment over a circular microaperture. The microaperture creates a fluid path from the overlying artificial endolymph (AE) bath to the underlying microfluidics channel (test bath) perfused with variants of artificial endolymph having variable $\mathrm{KCl}$ concentrations. $(C)$ The potential difference between the two baths was recorded over time with $\mathrm{Ag} / \mathrm{AgCl}$ electrodes placed in contact with two baths. $(D)$ Voltage was plotted as a function of the test bath concentration with best fit estimates (solid line) yielding the fixed charge concentration of the TM $(-7.1 \mathrm{mmol} / \mathrm{L} ; n=5 \mathrm{TM}$ preparations). ( $E$ ) The microaperture setup in panel $B$ was used to deliver electric fields to the TM with a pair of $\mathrm{Ag} / \mathrm{AgCl}$ stimulating electrodes. $(F)$ Electrically evoked displacements of the TM were nanoscale in amplitude and decreased with increasing stimulus frequency $(40-1000 \mathrm{~Hz}) .(G)$ Phase angle of TM displacements as a function of stimulus frequency remained flat around $-\pi / 2$. (Panels $A-G$ reprinted, with permission, from Ghaffari et al. 2013.) 
J.B. Sellon et al.

TM has proven difficult (Steel 1983). Such measurements are complicated by the fact that the TM lacks an insulating cell membrane layer, thus making it difficult for the tip of a microelectrode to be topologically inside the TM. To overcome the challenges associated with microelectrode techniques, Ghaffari et al. (2013) developed a technique whereby isolated TM segments were mounted in a two-compartment chamber containing a microaperture $(15 \mu \mathrm{m}$ radius) connecting the two compartments. The potential difference between the two-fluid microchannel and the top bath arises primarily from Donnan potentials that form between each bath and the TM, because of the presence of a fixed charge (Fig. 3B). If the two baths have identical compositions, the Donnan potential between the TM and each bath is identical, so the net potential difference between baths is zero. If one bath has a lower ionic concentration, the magnitude of the Donnan potential increases, so the potential difference between baths deviates from zero in a manner that depends on $c_{f}$ within the TM (Fig. 3C) consistent with Donnan theory (Fig. 3D) (Ghaffari et al. 2013).

The presence of fixed charge in the TM suggests the possibility that electrical stimuli might generate a mechanical response. The application of oscillating electric fields at audio frequencies $(1-1000 \mathrm{~Hz})$ was found to generate displacements of the TM in a microaperture chamber (Fig. 3E). TM displacements had peak amplitudes at positions on the undersurface of the TM locally above the microaperture. Displacement amplitudes dropped significantly with distance away from the microaperture, increased with electric field strength, and decreased as a function of stimulus frequency, consistent with viscous dominated interactions (Fig. 3F,G).

TM electrokinetics raises the intriguing notion that the TM may not behave as a purely mechanical structure locally but, instead, shows frequency-dependent electromechanical properties across multiple rows of hair cells. This electrically evoked motion may be driven by local interactions with the hair bundles of outer hair cells (OHCs), which are inserted into the TM. It is thus important to note that $\mathrm{OHC}$ bundles have been shown to generate mechanical forces in response to deflections (Jia and $\mathrm{He}$ 2005; Ashmore 2008). Such forces could contribute to the local motions of the TM, or may be enhanced by the mechanoelectrical transduction currents, which could exert electrokinetic forces locally near the surface of the TM (Ghaffari et al. 2013).

\section{RADIAL FIBRILLAR STRUCTURE AND WAVE MECHANICS}

In addition to its local porosity and electromechanical properties, the radial fibrillar structure of the TM may also play an important role in cochlear mechanics. Several studies have examined how the radial fibrillar structure of the TM might contribute to its mechanical properties. For example, to apply shear motions in the directions relevant to hair bundle mechanics, magnetic beads (Abnet and Freeman 2000) and microfabricated shearing probes ( $\mathrm{Gu}$ et al. 2005) have been used. Both of these techniques show that the TM is a viscoelastic tissue that can spatially couple motions in both the radial and longitudinal directions. Furthermore, these studies have shown that the TM is stiffer in the radial direction (along the fibrils) than in the longitudinal direction. In addition to shear probes, TM material properties have been determined from point indentations with AFM cantilevers (Shoelson et al. 2004; Gueta et al. 2006; Richter et al. 2007). Recently, AFM cantilevers were used to determine viscoelastic properties of the TM at audio frequencies (Gavara and Chadwick 2010). The techniques described thus far have characterized the local material properties of the TM relevant to hair bundle mechanics. However, the organ of Corti is longitudinally coupled by the TM, suggesting that bulk measurements of the TM are important. Recently, Lee et al. (2016) showed significant radial motion of the TM in vivo, which is exaggerated by $\alpha$-tectorin mutation, Tecta ${ }^{\mathrm{C} 1509 \mathrm{G} / \mathrm{C} 1509 \mathrm{G}}$, consistent with the observation of a reduced limbal attachment in this mutant (Xia et al. 2010). These results show the importance of the TM's bulk, radial structure in mechanical stimulation of $\mathrm{OHC}$ for proper maintenance of cochlear turning. To further examine how the radial fibrillar struc- 
TM Mechanical Properties and Functions

A

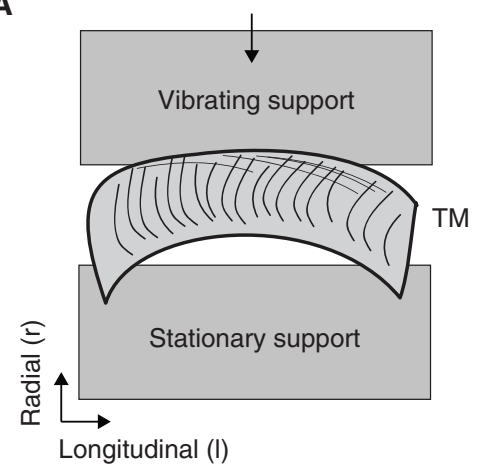

C

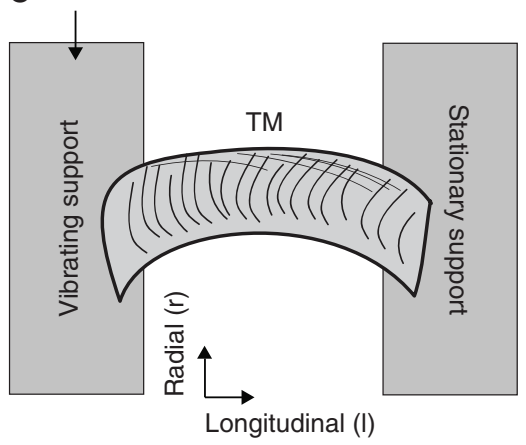

B

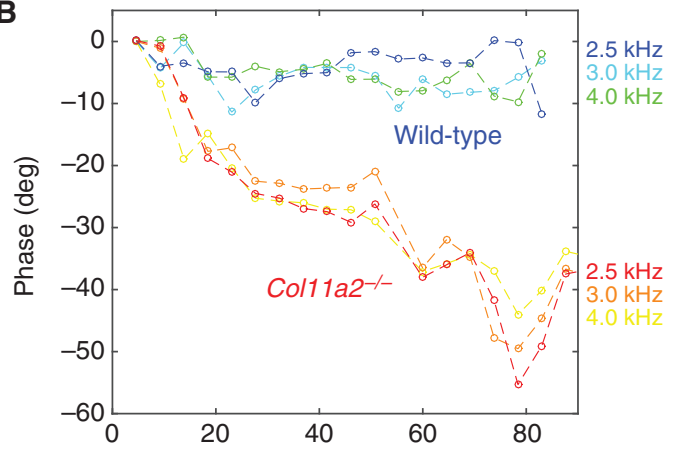

D

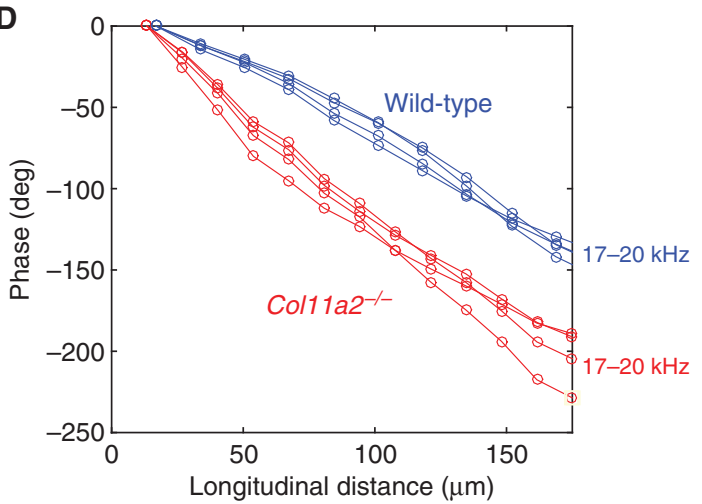

Figure 4. Compressional radial waves and longitudinal traveling waves in Col11a2 mutant tectorial membranes (TMs). (A) Wave chamber setup depicting stimulation of compressional waves along the radial direction of the TM. (B) Phase accumulation of motion along the TM's radial fibrillar structure. Deletion of Col1 1a2 increases the amount of phase accumulation along the radial direction and thus could impact outer hair cell (OHC)-inner hair cell (IHC) coupling mechanisms. (C) Wave chamber setup depicting stimulation of longitudinal traveling waves along the TM. (D) Deletion of Col11a2 increases the amount of phase accumulation along the longitudinal direction and thus reduces TM traveling wave speed. Reduced TM wave speed may cause mismatches with basilar membrane $(\mathrm{BM})$ wave speed and thus affect the sensitivity of hearing in Col11a2 $2^{-/-}$mice.

ture of the TM affects the TMs global mechanical properties, JB Sellon, R Ghaffari, DM Freeman, et al. (in prep.) recently explored traveling waves in Coll1a2 $2^{-1-}$ mutant mice. Transgenic mice lacking Col11 a2 have 40-50 dB threshold elevation measured at the brainstem (McGuirt et al. 1999), which is thought to be attributable to a disruption in the TM's collagen fibrils and its radial fibrillar structure. Compressional waves in the radial direction of TMs excised from wild-type and Coll1a2 $2^{-/-}$mutant mice propagate between the limbal and marginal zones (Fig. $4 \mathrm{~A}, \mathrm{~B})$. Coll1 $12^{-1-}$ mice have increased phase accumulation in the radial direction (along the collagen fibrils) compared with wild-type TMs. In addition to phase accumulation in the radial direction, Col11a2 $2^{-/-}$mice have increased phase accumulation in the longitudinal direction, and thus reduced longitudinal wave speed. The radial fibrillar structure of the TM is thus an important physical feature that controls both longitudinal and radial coupling phenomena.

\section{LONGITUDINAL COUPLING VIA TRAVELING WAVES}

In addition to radial motion, the TM has been shown to propagate longitudinally propagating waves in computational models (Meaud and Grosh 2010; Sellon et al. 2017), in vitro (Ghaffari 
J.B. Sellon et al.
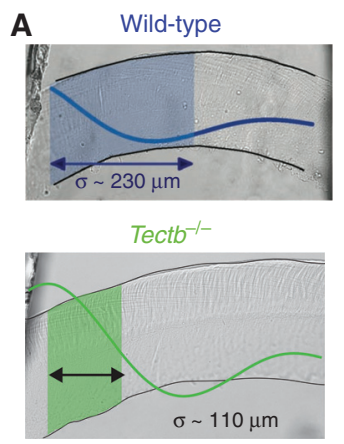

Tecta $^{\mathrm{Y} 1870 \mathrm{C} /+}$
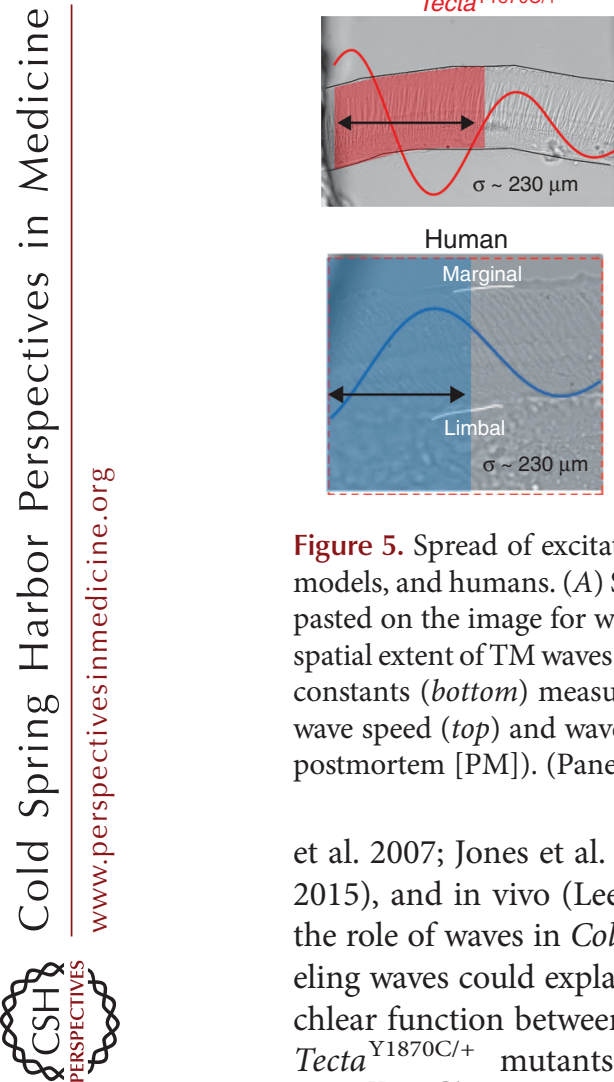
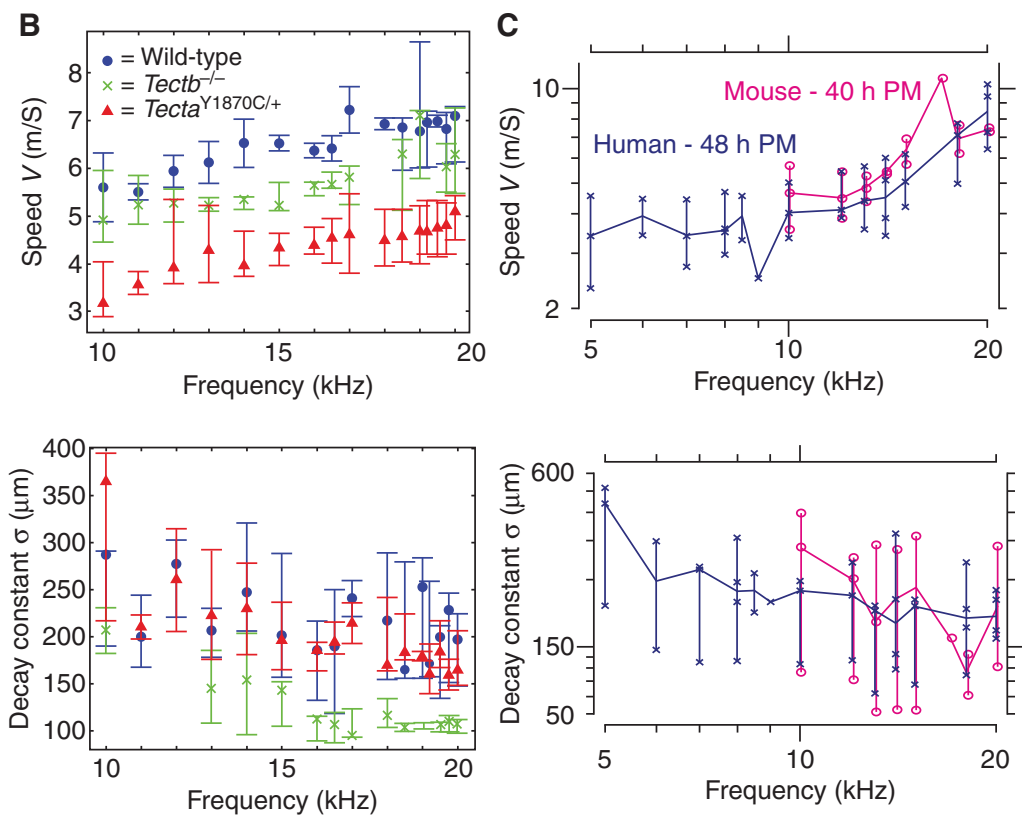

Figure 5. Spread of excitation via tectorial membrane (TM) traveling waves in wild-type mice, mutant mouse models, and humans. (A) Snapshots of TMs mounted in the wave chamber with an exponentially decaying wave pasted on the image for wild-type, Tect $b^{-/-}$, Tecta $^{\mathrm{Y} 1870 \mathrm{C} /+}$, and human TMs. The decaying wave highlights the spatial extent of TM waves at a given frequency. (B) Pooled datasets showing TM wave speed (top) and wave decay constants (bottom) measured across wild-type, Tecta ${ }^{\mathrm{Y} 1870 \mathrm{C} /+}$, and Tectb ${ }^{-/-}$TMs. $(C)$ Pooled datasets for TM wave speed (top) and wave decay constants (bottom) for human TMs compared with mouse TMs (tested $48 \mathrm{~h}$ postmortem [PM]). (Panels adapted from data in Sellon et al. 2014 and Farrahi et al. 2016.)

et al. 2007; Jones et al. 2013; Sellon et al. 2014, 2015), and in vivo (Lee et al. 2015). Similar to the role of waves in Col11a2 $2^{-1-}$ mice, TM traveling waves could explain the differences in cochlear function between both the Tectb ${ }^{-1-}$ and Tecta ${ }^{\mathrm{Y} 1870 \mathrm{C} /+}$ mutants and the wild types. Tecta ${ }^{\mathrm{Y} 1870 \mathrm{C} /+}$ mutants, in particular, have normal hair bundles, TM attachments, and basilar membrane (BM) sensitivity response, but show reduced neural sensitivity (Russell et al. 2007), which cannot be explained by changes in TM point stiffness alone. Recent measurements (Sellon et al. 2014) at audio frequencies show that TM shear viscosity is significantly lower in Tecta ${ }^{\mathrm{Y} 1870 \mathrm{C} /+} \mathrm{TM}$ than in wild-type TMs, owing to larger nanopores (Fig. 5A,B). Reducing TM shear viscosity (via increased pore size) reduced wave transmission losses, which, in turn, facilitated TM waves to propagate with larger decay constants in Tecta ${ }^{\mathrm{Y} 1870 \mathrm{C} /+}$ mutants.

$\mathrm{Tectb}^{-/-}$mutant mice, which lack the $\beta$-tectorin glycoproteins, show a striking phenotype that differs from Tecta ${ }^{\mathrm{Y} 1870 \mathrm{C} /+}$ and Col11a2 $2^{-/-}$ mutants. They have reduced sensitivity and sharper BM tuning (Russell et al. 2007). These differences in sensitivity and tuning cannot be explained by changes in cochlear amplification. However, this combination of hearing abnormalities was found to be consistent with measured changes in TM wave decay constants. Ghaffari et al. (2010) showed that TM waves in Tect $b^{-/-}$mice have smaller decay constants by a factor of two, suggesting that differences in TM waves may underlie differences in longitudinal coupling. These findings together show that the TM is not a purely elastic structure, but rather it 
TM Mechanical Properties and Functions

has important wave properties that account for differences in cochlear tuning phenotypes of Tecta ${ }^{\mathrm{Y} 1870 \mathrm{C} /+}$ and $\mathrm{Tectb}^{-/-}$mutant mice.

\section{IMPLICATIONS FOR HEARING MECHANISMS}

TM wave results in mutant mouse models raised the intriguing possibility that neural frequency tuning in humans may be sharper attributable in part to differences in TM longitudinal coupling and wave mechanics. To determine whether TM wave properties underlie sharper tuning in humans (Shera and Charaziak 2018), Farrahi et al. (2016) conducted the first direct measurements on freshly excised human TMs. Their in vitro results showed that spatial decay constants for both mice and humans were on the order of $150 \mu \mathrm{m}$ at $20 \mathrm{kHz}$ (Fig. 5C). This distance is a measure of longitudinal spread of excitation, which has been shown to correlate with spectral spread of excitation. In mice, the spatial spread of $\sim 150 \mu \mathrm{m}$ corresponds to a frequency spread of $1.6 \mathrm{kHz}$ and therefore a quality of tuning $\mathrm{Q}_{10 \mathrm{~dB}}$ of $\sim 10$ at $20 \mathrm{kHz}$. In Tectb knockout mice, the decay constant of TM waves is approx-

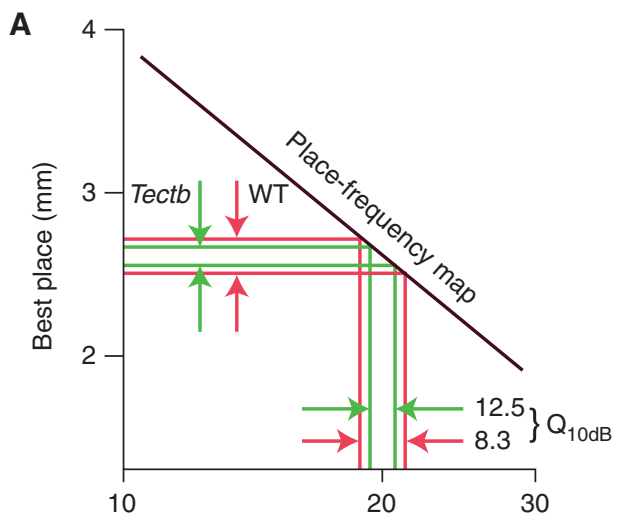

B
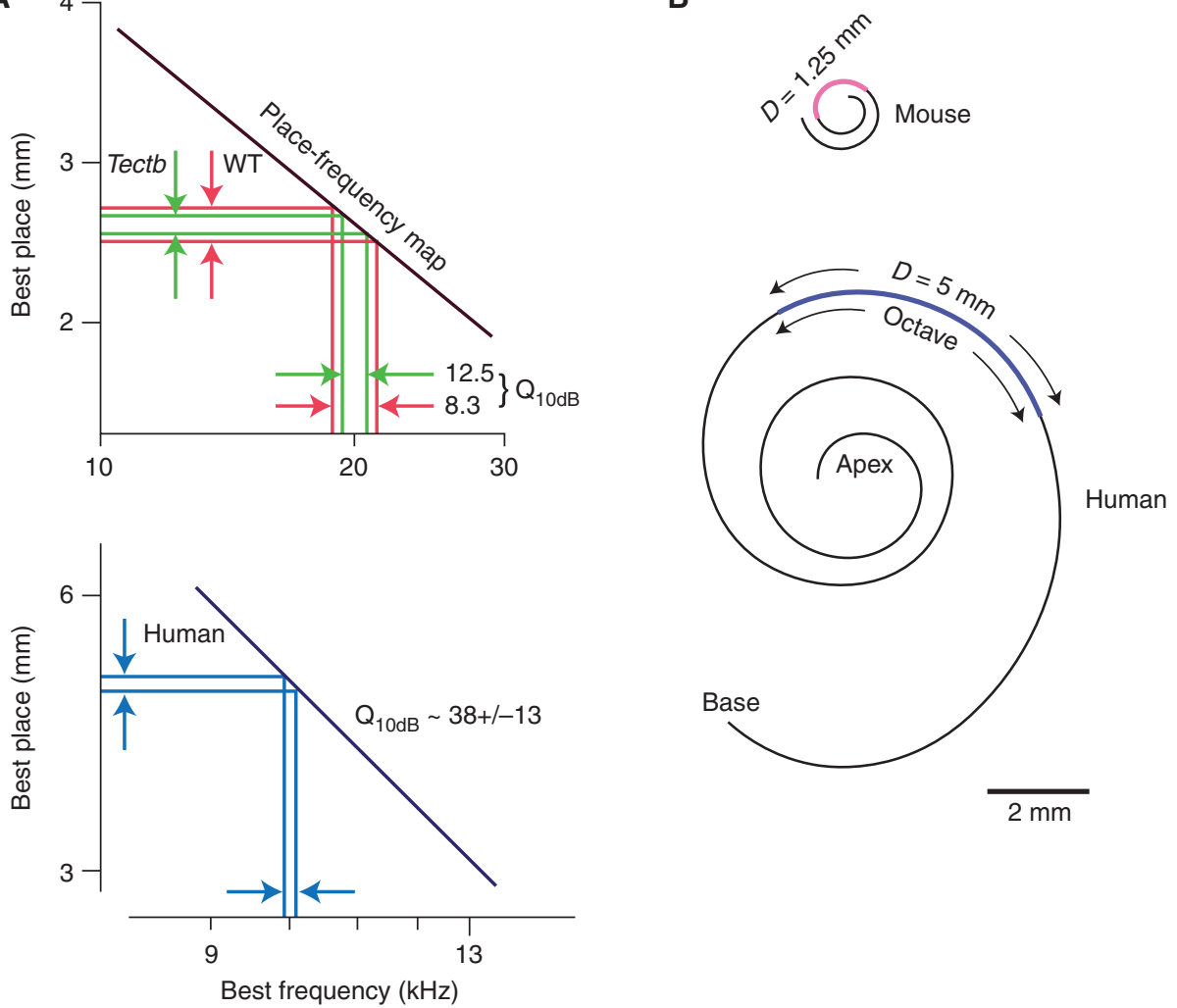

Figure 6. Tectorial membrane (TM) wave properties correlate with frequency tuning via a place-frequency map of the cochlea in wild-type mice, mutant mouse models, and humans. (A) Place-frequency maps of wild-type and mutant mice (top) compared with humans (bottom), showing the relationship between the spread of the TM wave and the frequency spread. Sharpness of frequency tuning $\left(\mathrm{Q}_{10 \mathrm{~dB}}\right)$ was larger in human $\mathrm{TMs}\left(\mathrm{Q}_{10 \mathrm{~dB}} \sim 38\right)$ compared with $\mathrm{Tectb}^{-1-}\left(\mathrm{Q}_{10 \mathrm{~dB}} \sim 12.5\right)$ and wild-type mice $\left(\mathrm{Q}_{10 \mathrm{~dB}} \sim 8.3\right)$. (Panel $A$ [top] reprinted, with permission, from Sellon et al. 2014.) (B) Schematic drawings of cochlear spirals in human and mouse. The spatial extents of octave intervals as calculated from the cochlear maps of Greenwood (1990) and Muller et al. (2005) are indicated with colored lines along the spiral. WT, wild type. (Panel B reprinted, with permission, from Farrahi et al. 2016.) 
J.B. Sellon et al.

imately halved, leading to a $\mathrm{Q}_{10 \mathrm{~dB}}$ value that is doubled. This sharpened tuning, predicted from the mechanical spread of excitation measured in an isolated TM, correlates well with sharpened tuning in auditory nerve measurements of these mutant mice. Although TM waves spread excitations over similar distances in mice and humans (Fig. 6A,B), these distances span significantly different ranges of frequencies. This difference has important implications for our ability to separate sounds by their frequency content, suggesting that the spread of excitation via TM traveling waves is broader in mice than in humans. It is therefore important to characterize the spread of excitation in terms of the range of frequencies over which the excitation is spread. In addition to measurements on isolated TMs, Dewey et al. (2018) show that reduction in hair bundle stiffness sharpens cochlear tuning by decreasing the spread of excitation through the TM traveling wave in vivo. Thus, these results have shown that the spatial extent of TM waves strongly correlates with cochlear tuning in humans, mice, and likely other mammals, suggesting that the TM is essential for contributing to cochlear sensitivity and frequency selectivity.

\section{CONCLUSIONS}

The findings presented in this review show that the TM is a highly porous, hydrated, and dynamic structure. The poroelastic, electrokinetic, and wave properties of the TM are frequency and place dependent and thereby may be essential for cochlear sensitivity and frequency selectivity. Future research directions in imaging, nanoscale mechanics, and electrokinetic measurements will help further advance our understanding of TM local, radial, and longitudinal cochlear interactions, with direct implications for cochlear mechanisms.

\section{REFERENCES}

${ }^{*}$ Reference is also in this collection.

Abnet CC, Freeman DM. 2000. Deformations of the isolated mouse tectorial membrane produced by oscillatory forces. Hear Res 144: 29-46.
Andrade LR, Salles FT, Grati M, Manor U, Kachar B. 2016. Tectorins crosslink type II collagen fibrils and connect the tectorial membrane to the spiral limbus. J Struct Biol 194: 139-146.

Ashmore J. 2008. Cochlear outer hair cell motility. Physiol Rev 88: 173-210.

Cheatham MA, Goodyear RJ, Homma K, Legan PK, Korchagina J, Naskar S, Siegel JH, Dallos P, Zheng J, Richardson GP. 2014. Loss of the tectorial membrane protein CEACAM16 enhances spontaneous, stimulus-frequency, and transiently evoked otoacoustic emissions. J Neurosci 34: 10325-10338.

Dewey JB, Xia A, Müller U, Belyantseva IA, Applegate BE, Oghalai JS. 2018. Mammalian auditory hair cell bundle stiffness affects frequency tuning by increasing coupling along the length of the cochlea. Cell Rep 23: 2915-2927.

Farrahi S, Ghaffari R, Sellon JB, Nakajima HH, Freeman DM. 2016. Tectorial membrane traveling waves underlie sharp auditory tuning in humans. Biophys J 111: 921-924.

Freeman D, Masaki K, McAllister A, Wei J, Weiss T. 2003. Static material properties of the tectorial membrane: A summary. Hear Res 180: 11-27.

Gavara N, Chadwick RS. 2010. Noncontact microrheology at acoustic frequencies using frequency-modulated atomic force microscopy. Nat Methods 7: 650-654.

Ghaffari R, Aranyosi AJ, Freeman DM. 2007. Longitudinally propagating traveling waves of the mammalian tectorial membrane. Proc Natl Acad Sci 104: 16510-16515.

Ghaffari R, Aranyosi AJ, Richardson GP, Freeman DM. 2010. Tectorial membrane traveling waves underlie abnormal hearing in Tectb mutants. Nat Commun 1: 96.

Ghaffari R, Page SL, Farrahi S, Sellon JB, Freeman DM. 2013. Electrokinetic properties of the mammalian tectorial membrane. Proc Natl Acad Sci 110: 4279-4284.

Goodyear RJ, Lu X, Deans MR, Richardson GP. 2017. A tectorin-based matrix and planar cell polarity genes are required for normal collagen-fibril orientation in the developing tectorial membrane. Development 144: 3978 3989.

Greenwood DD. 1990. A cochlear frequency-position function for several species-29 years later. J Acoust Soc Am 87: 2592-2605.

Gu JW, Aranyosi AJ, Hemmert W, Freeman DM. 2005. Measuring mechanical properties of the isolated tectorial membrane at audio frequencies with a microfabricated probe. In Abstracts of the Twenty-Eighth Midwinter Research Meeting of Association for Research in Otolaryngology. New Orleans, LA.

Gu JW, Hemmert W, Freeman DM, Aranyosi AJ. 2008. Frequency-dependent shear impedance of the tectorial membrane. Biophys J 95: 2529-2538.

Gueta R, Barlam D, Shneck RZ, Rousso I. 2006. Measurement of the mechanical properties of isolated tectorial membrane using atomic force microscopy. Proc Natl Acad Sci 103: 14790-14795.

Jia S, He DZ. 2005. Motility-associated hair-bundle motion in mammalian outer hair cells. Nat Neurosci 8: 10281034.

Jones GP, Lukashkina VA, Russell IJ, Elliott SJ, Lukashkin AN. 2013. Frequency-dependent properties of the tecto- 
TM Mechanical Properties and Functions

rial membrane facilitate energy transmission and amplification in the cochlea. Biophys J 104: 1357-1366.

Killick R, Legan PK, Malenczak C, Richardson GP. 1995. Molecular cloning of chick $\beta$-tectorin, an extracellular matrix molecule of the inner ear. J Cell Biol 129: 535-547.

Lee HY, Raphael PD, Park J, Ellerbee AK, Applegate BE, Oghalai JS. 2015. Noninvasive in vivo imaging reveals differences between tectorial membrane and basilar membrane traveling waves in the mouse cochlea. Proc Natl Acad Sci 112: 3128-3133.

Lee HY, Raphael PD, Xia A, Kim J, Grillet N, Applegate BE, Ellerbee Bowden AK, Oghalai JS. 2016. Two-dimensional cochlear micromechanics measured in vivo demonstrate radial tuning within the mouse organ of corti. J Neurosci 36: 8160-8173.

Legan PK, Lukashkina VA, Goodyear RJ, Kössl M, Russell IJ, Richardson GP. 2000. A targeted deletion in $\alpha$-tectorin reveals that the tectorial membrane is required for the gain and timing of cochlear feedback. Neuron 28: 273285.

Legan PK, Lukashkina VA, Goodyear RJ, Lukashkin AN Verhoeven K, Camp GV, Russell IJ, Richardson GP. 2005. A deafness mutation isolates a second role for the tectorial membrane in hearing. Nat Neurosci 8: 10351042.

Legan PK, Goodyear RJ, Morín M, Mencia A, Pollard H, Olavarrieta L, Korchagina J, Modamio-Hoybjor S, Mayo F, Moreno F, et al. 2014. Three deaf mice: Mouse models for tecta-based human hereditary deafness reveal domain-specific structural phenotypes in the tectorial membrane. Hum Mol Gen 23: 2551-2568.

Masaki K, Weiss TF, Freeman DM. 2006. Poroelastic bulk properties of the tectorial membrane measured with osmotic stress. Biophys J 91: 2356-2370.

McGuirt WT, Prasad SD, Griffith AJ, Kunst HP, Green GE, Shpargel KB, Runge C, Huybrechts C, Mueller RF, Lynch E, et al. 1999. Mutations in COL11A2 cause non-syndromic hearing loss (DFNA13). Nat Genet 23: 413-419.

Meaud J, Grosh K. 2010. The effect of tectorial membrane and basilar membrane longitudinal coupling in cochlear mechanics. J Acoust Soc Am 127: 1411-1421.

Muller M, von Hunerbein K, Hoidis S, Smolders JW. 2005. A physiological place-frequency map of the cochlea in CBA/J mouse. Hear Res 202: 63-73.
Nia HT, Han L, Li Y, Ortiz C, Grodzinsky A. 2011. Poroelasticity of cartilage at the nanoscale. Biophys $J$ 101: 2304-2313.

Nia HT, Han L, Bozchalooi IS, Roughley P, Youcef-Toumi K, Grodzinsky AJ, Ortiz C. 2015. Aggrecan nanoscale solidfluid interactions are a primary determinant of cartilage dynamic mechanical properties. ACS Nano 9: 2614-2625.

Richter CP, Emadi G, Getnick G, Quesnel A, Dallos P. 2007. Tectorial membrane stiffness gradients. Biophys J 93: 2265-2276.

Russell IJ, Legan PK, Lukashkina VA, Lukashkin AN, Goodyear RJ, Richardson GP. 2007. Sharpened cochlear tuning in a mouse with a genetically modified tectorial membrane. Nat Neurosci 10: 215-223.

Sellon JB, Ghaffari R, Farrahi S, Richardson GP, Freeman DM. 2014. Porosity controls spread of excitation in tectorial membrane traveling waves. Biophys J 106: 1406-1413.

Sellon JB, Farrahi S, Ghaffari R, Freeman DM. 2015. Longitudinal spread of mechanical excitation through tectorial membrane traveling waves. Proc Natl Acad Sci 112: 12968-12973.

Sellon JB, Ghaffari R, Freeman DM. 2017. Geometric requirements for tectorial membrane traveling waves in the presence of cochlear loads. Biophys J 112: 1059-1062.

* Shera CA, Charaziak KK. 2018. Cochlear frequency tuning and otoacoustic emissions. Cold Spring Harb Perspect Med doi: 10.1101/cshperspect.a033498.

Shoelson B, Dimitriadis EK, Cai H, Kachar B, Chadwick RS. 2004. Evidence and implications of inhomogeneity in tectorial membrane elasticity. Biophys J 87: 2768-2777.

Steel KP. 1983. Donnan equilibrium in the tectorial membrane. Hear Res 12: 265-272.

von Békésy G. 1960. Experiments in hearing. McGraw-Hill, New York.

Xia A, Gao SS, Yuan T, Osborn A, Bress A, Pfister M, Maricich SM, Pereira FA, Oghalai JS. 2010. Deficient forward transduction and enhanced reverse transduction in the $\alpha$ tectorin C1509G human hearing loss mutation. Dis Model Mech 3: 209-223.

Zwislocki JJ. 1980. Five decades of research on cochlear mechanics. J Acoust Soc Am 67: 1679-1685.

Zwislocki JJ, Cefaratti LK. 1989. Tectorial membrane. II: Stiffness measurements in vivo. Hear Res 42: 211-227. 


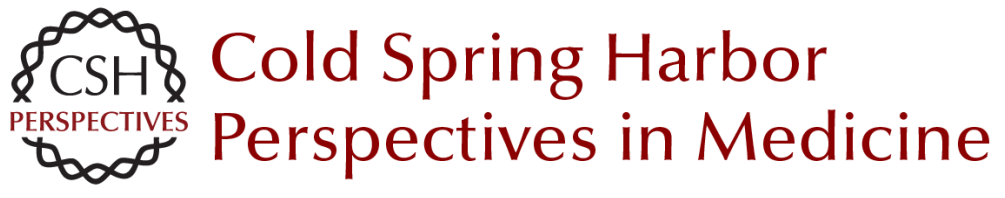

\section{The Tectorial Membrane: Mechanical Properties and Functions}

Jonathan B. Sellon, Roozbeh Ghaffari and Dennis M. Freeman

Cold Spring Harb Perspect Med 2019; doi: 10.1101/cshperspect.a033514 originally published online October 22, 2018

\section{Subject Collection Function and Dysfunction of the Cochlea}

Hidden Hearing Loss: A Disorder with Multiple Etiologies and Mechanisms

David C. Kohrman, Guoqiang Wan, Luis Cassinotti, et al.

Hair Cell Afferent Synapses: Function and Dysfunction

Stuart L. Johnson, Saaid Safieddine, Mirna Mustapha, et al.

Active Biomechanics of Sensory Hair Bundles Dolores Bozovic

The Tectorial Membrane: Mechanical Properties and Functions

Jonathan B. Sellon, Roozbeh Ghaffari and Dennis M. Freeman

The Epidemiology of Deafness Abraham M. Sheffield and Richard J.H. Smith

Toward the Optical Cochlear Implant Tobias Dombrowski, Vladan Rankovic and Tobias Moser

Outer Hair Cells and Electromotility Jonathan Ashmore

Interactions between Macrophages and the Sensory Cells of the Inner Ear Mark E. Warchol
Development and Patterning of the Cochlea: From Convergent Extension to Planar Polarity Mireille Montcouquiol and Matthew W. Kelley

Hair-Bundle Links: Genetics as the Gateway to Function Guy P. Richardson and Christine Petit

Aminoglycoside- and Cisplatin-Induced Ototoxicity: Mechanisms and Otoprotective Strategies

Corné J. Kros and Peter S. Steyger

Function and Dysfunction of TMC Channels in Inner Ear Hair Cells

David P. Corey, Nurunisa Akyuz and Jeffrey R. Holt

Cochlear Gene Therapy

Lawrence Lustig and Omar Akil

Age-Related Hearing Loss

Michael R. Bowl and Sally J. Dawson

Inner Ear Connexin Channels: Roles in Development and Maintenance of Cochlear Function Fabio Mammano

A Functional Perspective on the Evolution of the Cochlea Christine Köppl and Geoffrey A. Manley

For additional articles in this collection, see http://perspectivesinmedicine.cshlp.org/cgi/collection/ 